\title{
A note on arterial to venous oxygen saturation as reference for NIRS-determined frontal lobe oxygen saturation in healthy humans
}

\author{
Henrik Sørensen*, Niels H. Secher and Peter Rasmussen \\ Department of Anesthesia, The Copenhagen Muscle Research Center, Rigshospitalet, University of Copenhagen, Copenhagen, Denmark \\ *Correspondence: hs770@hotmail.com \\ Edited by: \\ Patrice Brassard, Laval University, Canada \\ Reviewed by: \\ J. Patrick Neary, University of Regina, Canada
}

Keywords: cerebral oxygenation, humans, hypocapnia, hypercapnia, hypoxia, jugular vein, NIRS

Near infrared spectroscopy (NIRS) offers non-invasive assessment of oxygenation within the human brain $\left(\mathrm{S}_{\mathrm{c}} \mathrm{O}_{2}\right)$ by appreciating the different absorption of near infrared light by hemoglobin and oxyhemoglobin (Jobsis, 1977). Since the length the light has passed when traveling from the skin to the cortex and then returning to the skin remains unknown, there is a need to adjust the signal according to an assumed ratio between the arterial vs. venous blood that is appreciated. Apparently, most NIRS devices use a fixed reference ratio between the arterial $(25 \%)$ and venous contribution $(75 \%)$ to the signal despite not eligible mismatch (Bickler et al., 2013). This assumption is based on anatomical evidence (Pollard et al., 1996), but might be confounded by changes in cerebral blood volume during, e.g., hypoxia and changes in the arterial carbon dioxide tension $\left(\mathrm{P}_{\mathrm{a}} \mathrm{CO}_{2}\right)$ (Ito et al., 2005). A standard reference arterial to venous ratio may therefore not exist for application of NIRS to determine $\mathrm{S}_{\mathrm{c}} \mathrm{O}_{2}$ in humans. Thus, an estimate of cerebral capillary hemoglobin oxygen saturation $\left(\mathrm{S}_{\text {cap }} \mathrm{O}_{2}\right)$ to express cerebral oxygenation is based on $50 \%$ jugular and arterial saturations (Gjedde et al., 2005) and has been reported to follow changes in $\mathrm{S}_{\mathrm{c}} \mathrm{O}_{2}$ (Rasmussen et al., 2007). In this report we made a meta-analysis on published data (Rasmussen et al., 2007; Sørensen et al., 2012, in press) in order to evaluate which ratio between arterial and internal jugular venous hemoglobin saturation that fits best to the concomitant determined $\mathrm{S}_{\mathrm{c}} \mathrm{O}_{2}$ in healthy humans exposed to a wide range of interventions.
Thirty seven subjects [age 27(9) years, height $181(10) \mathrm{cm}$, mass $79(13) \mathrm{kg}$, mean $(S D)]$ were catheterized in the right internal jugular vein with the tip of the catheter advanced to the bulb of the vein and with a catheter in the brachial artery of the nondominant arm, while $\mathrm{S}_{\mathrm{c}} \mathrm{O}_{2}$ was monitored by the Invos Cerebral Oximetry (Covidien, Mansfield, MI). Arterial partial pressure for oxygen and carbon dioxide, and oxygen saturations were measured in the jugular and arterial blood $\left(\mathrm{P}_{\mathrm{a}} \mathrm{O}_{2} ; \mathrm{P}_{\mathrm{a}} \mathrm{CO}_{2} ; \mathrm{S}_{\mathrm{a}} \mathrm{O}_{2}\right.$; $\mathrm{S}_{\mathrm{j}} \mathrm{O}_{2}$ ) (ABL-800, Radiometer, Brønshøj, Denmark). The subjects were exposed to hypoxia $\left(\mathrm{F}_{\mathrm{i}} \mathrm{O}_{2}=10 \% ; n=23\right)$, inspiration of $100 \%$ oxygen $(n=8)$, atmospheric air $(n=37)$, hypercapnia $\left(\mathrm{F}_{\mathrm{i}} \mathrm{CO}_{2}=5 \%\right.$; $n=8)$ and asked to hyperventilate $(\sim 2-$ $3 \mathrm{kPa}$ reduction in $\mathrm{P}_{\mathrm{a}} \mathrm{CO}_{2} ; n=32$ ) with separate controls. By linear regression the contribution from arterial and jugular blood to $\mathrm{S}_{\mathrm{c}} \mathrm{O}_{2}$ was estimated and $\mathrm{R}$ squared $\left(R^{2}\right)$ and root mean square error (RMSE) between $\mathrm{S}_{\mathrm{c}} \mathrm{O}_{2}$ and the arterial fraction in the reference saturation were calculated (SAS Institute Inc., Cary, NC). Only data points where $\mathrm{S}_{\mathrm{j}} \mathrm{O}_{2} \leq \mathrm{S}_{\mathrm{c}} \mathrm{O}_{2} \leq$ $\mathrm{S}_{\mathrm{a}} \mathrm{O}_{2}$ were included. All reference saturations were calculated, e.g., $\mathrm{S}_{\text {cap }} \mathrm{O}_{2}=0.50$. $\mathrm{S}_{\mathrm{a}} \mathrm{O}_{2}+0.50 \cdot \mathrm{S}_{\mathrm{j}} \mathrm{O}_{2}$. The following equation, $0=\mathrm{S}_{\mathrm{c}} \mathrm{O}_{2}-\left[\mathrm{a} \cdot \mathrm{S}_{\mathrm{a}} \mathrm{O}_{2}+(\mathrm{a}-\right.$ 1) $\left.\cdot \mathrm{S}_{\mathrm{j}} \mathrm{O}_{2}\right]$, was used to calculate the arterial fraction (a) for which the difference between $\mathrm{S}_{\mathrm{c}} \mathrm{O}_{2}$ and the reference saturation was zero.

$\mathrm{S}_{\mathrm{a}} \mathrm{O}_{2}$ and $\mathrm{S}_{\mathrm{j}} \mathrm{O}_{2}$ ranged from 70 to $100 \%$ and 33 to $87 \%$, respectively, while $\mathrm{S}_{\mathrm{c}} \mathrm{O}_{2}$ ranged from 48 to $95 \% . \mathrm{P}_{\mathrm{a}} \mathrm{CO}_{2}$ was manipulated from 1.6 to $6.3 \mathrm{kPa}$. According to the linear regression analysis,
$\mathrm{S}_{\mathrm{c}} \mathrm{O}_{2}$ demonstrated a correlation to a wide range of ratios between the arterial and venous hemoglobin saturations. The highest RMSE was obtained when it was considered that there was no arterial contribution to $\mathrm{S}_{\mathrm{c}} \mathrm{O}_{2}$ and the RMSE became gradually lower when the arterial contribution was considered to increase (Figure 1A). The lowest RMSE was observed for a $75 \%$ arterial and $25 \%$ jugular venous blood contribution to $\mathrm{S}_{\mathrm{c}} \mathrm{O}_{2}\left(\mathrm{RMSE}=2.70 ; R^{2}=0.644\right.$; $P<0.0001$; Figure 1A). For the oftenused calibration ratio $\left(25 \%\right.$ arterial) $R^{2}$ was $0.505(P<0.0001)$ with a RMSE of 4.233. In contrast, $\mathrm{S}_{\mathrm{cap}} \mathrm{O}_{2}(50 \%$ arterial $)$ had a $R^{2}$ of $0.606(P<0.0001$; RMSE $=3.276$; Figure 1A). Zero was within the $95 \%$ confidence interval only with a calculated $40-50 \%$ arterial contribution to the reference ratio. When $\mathrm{S}_{\mathrm{c}} \mathrm{O}_{2}$ was compared with the calibration ratio, the mean difference was zero in $2.9 \%$ of the blood samples, whereas it was $10.5 \%$ when $\mathrm{S}_{\text {cap }} \mathrm{O}_{2}$ was used as reference (Figure 1B).

This meta-analysis of published data suggests that the optimal reference ratio has a larger arterial contribution than the ratio defined by anatomical models and likely incorporated in most NIRS devices (Pollard et al., 1996; Bickler et al., 2013). The subjects were not only exposed to conditions that changes the venous oxygen saturation, i.e., hyperventilation, but also to conditions known to affect arterial and venous cerebral blood volume and oxygen content without influencing extracerebral blood (Ito et al., 2005). From these interventions, linear regression analysis demonstrated that the correlation between 


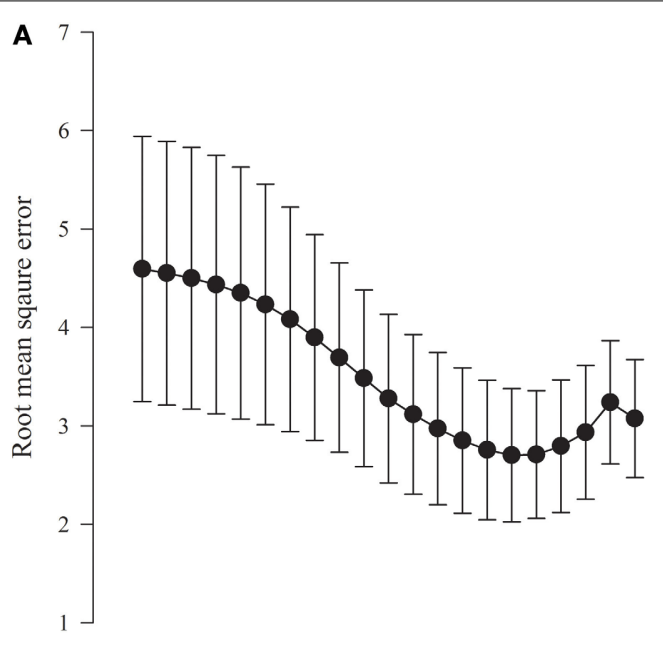

B

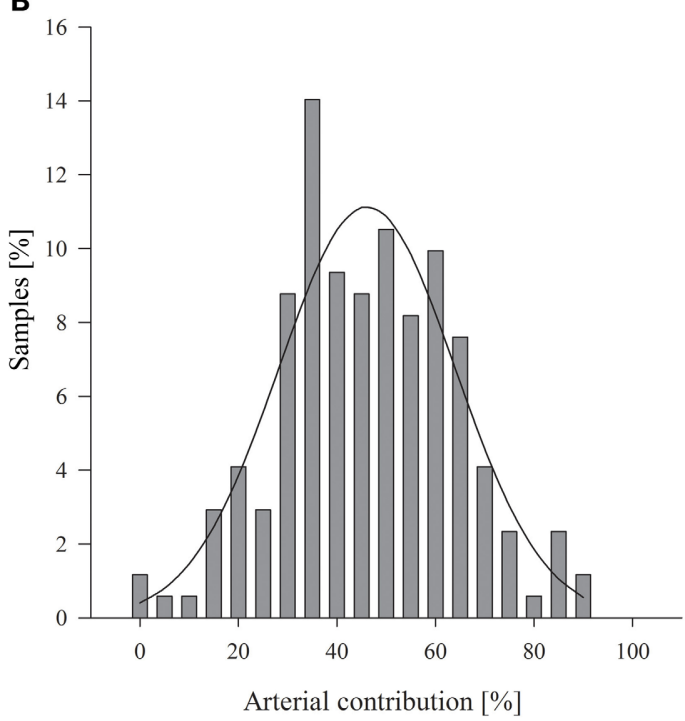

FIGURE 1 | (A) Root mean square error for the arterial fraction determined by the linear regression analysis. Values are mean (95\% confidence interval). (B) Zero difference between the Invos-determined cerebral oxygenation $\left(\mathrm{S}_{\mathrm{C}} \mathrm{O}_{2}\right)$ and the calculated reference saturation related to the considered arterial contribution for 171 blood samples; average arterial contribution $46 \pm 17 \%$ (SD). Solid line represents the distribution.

$\mathrm{S}_{\mathrm{c}} \mathrm{O}_{2}$ and the arterial contribution to the reference saturation was highest when a $75 \%$ arterial contribution was considered $\left(R^{2}=0.644\right)$ and also for that ratio the RMSE was the lowest (2.70) (Figure 1A). The calibration ratio (25\% arterial) typically incorporated in the algorithms had a $R^{2}$ of 0.505 and a RMSE of 4.233 while $\mathrm{S}_{\text {cap }} \mathrm{O}_{2}$ demonstrated a stronger correlation with a $R^{2}$ of $0.606(P<0.0001$; RMSE $=3.276)$. In addition, the mismatch between $\mathrm{S}_{\mathrm{c}} \mathrm{O}_{2}$ and the reference ratio was more likely to be zero when a more arterial weighted reference was applied (Figure 1B). Thus, our findings demonstrate that $\mathrm{S}_{\text {cap }} \mathrm{O}_{2}$ is an accurate reference for $\mathrm{S}_{\mathrm{c}} \mathrm{O}_{2}$ at least when determined with the Invos apparatus.

Similar to these findings, no eligible mismatch between $\mathrm{S}_{\mathrm{c}} \mathrm{O}_{2}$ values and the calibration ratio (25\% arterial) is observed in five different NIRS devices used to determine cerebral oxygenation in healthy subjects exposed to isocapnic hypoxemia (Bickler et al., 2013). Hypercapnia and isocapnic hypoxemia induce cerebral vasodilation and affect cerebral blood volume mainly by an increase in the arterial fraction (Ito et al., 2005). Thus, it is likely that the illuminated area of the brain encompasses more arterial blood and that could explain the aggravated mismatch between $\mathrm{S}_{\mathrm{c}} \mathrm{O}_{2}$ and the calibration ratio during hypoxia (Bickler et al., 2013). Cerebral blood flow and jugular venous oxygen saturation are decreased with hyperventilation that reduce the calibration ratio more compared to $\mathrm{S}_{\text {cap }} \mathrm{O}_{2}$. Interestingly, when healthy humans hyperventilate the $\mathrm{S}_{\mathrm{c}} \mathrm{O}_{2}$ overestimated the calibration ratio by $11.2 \%$ while the mean bias was only $0.2 \%$ for $\mathrm{S}_{\text {cap }} \mathrm{O}_{2}$ (Sørensen et al. unpublished). Thus, the mismatch between the calibration ratio and $\mathrm{S}_{\mathrm{c}} \mathrm{O}_{2}$ is aggravated when only jugular venous oxygen saturation is altered, which indicates that $\mathrm{S}_{\mathrm{c}} \mathrm{O}_{2}$ accounts for more than $25 \%$ arterial blood and that evaluations of reference saturations for NIRS must also involve conditions known to affect arterial oxygen content.

The arterial to venous balance within the brain may differ between individuals and explains the inter-individual variation in absolute $\mathrm{S}_{\mathrm{c}} \mathrm{O}_{2}$ readings (Rasmussen et al., 2007; Bickler et al., 2013), especially the heterogeneity of blood vessels in the illuminated area of the brain seems to affect light absorption because the photons are "lost" in major blood vessel, e.g., the sagittal sinuses (Kishi et al., 2003). Other factors affecting light absorption and thereby the $\mathrm{S}_{\mathrm{c}} \mathrm{O}_{2}$ readings may be variation in skull thickness and amount of cerebrospinal fluid (Yoshitani et al., 2007; Strangman et al., 2014). Also, skin pigmentation (Bickler et al., 2013) and degradation products of heme can affect $\mathrm{S}_{\mathrm{c}} \mathrm{O}_{2}$ because of competitive absorption of light (Madsen et al., 2000).

Despite absolute $\mathrm{S}_{\mathrm{c}} \mathrm{O}_{2}$ values are not comparable and exhibit large variations when compared to the calibration ratio, NIRS offers a unique non-invasive method for assessment of cerebral oxygen delivery vs. consumption and its clinical utility relies on changes from baseline rather than on absolute values (Murkin et al., 2007). Yet, at present the NIRS technology for evaluation of $\mathrm{S}_{\mathrm{c}} \mathrm{O}_{2}$ is limited when skin blood flow is affected either by scalp ischemia or administration of sympathomimetic agents that affect skin blood flow (Davie and Grocott, 2012; Sørensen et al., 2012).

In summary, this report suggests that the reference saturations applied when using Invos cerebral oximetry should be weighted more to arterial hemoglobin 
saturation than accepted by anatomical models.

\section{AUTHOR CONTRIBUTIONS}

All authors contributed equally to the design, data analysis, and interpretation, drafting the manuscript and critical revision. All authors approved the final version before submission.

\section{REFERENCES}

Bickler, P. E., Feiner, J. R., and Rollins, M. D. (2013). Factors affecting the performance of 5 cerebral oximeters during hypoxia in healthy volunteers. Anesth. Analg. 117, 813-823. doi: 10.1213/ANE.0b013e31829 $7 \mathrm{~d} 763$

Davie, S. N., and Grocott, H. P. (2012). Impact of extracranial contamination on regional cerebral oxygen saturation: a comparison of three cerebral oximetry technologies. Anesthesiology 116, 834-840. doi: 10.1097/ALN.0b013e $31824 \mathrm{c} 00 \mathrm{~d} 7$

Gjedde, A., Johannsen, P., Cold, G. E., and Østergaard, L. (2005). Cerebral metabolic response to low blood flow: possible role of cytochrome oxidase inhibition. J. Cereb. Blood Flow Metab. 25, 1183-1196. doi: 10.1038/sj.jcbfm.9600113

Ito, H., Ibaraki, M., Kanno, I., Fukuda, H., and Miura, S. (2005). Changes in the arterial fraction of human cerebral blood volume during hypercapnia and hypocapnia measured by positron emission tomography. J. Cereb. Blood Flow Metab. 25, 852-857. doi: 10.1038/sj.jcbfm. 9600076

Jobsis, F. F. (1977). Noninvasive, infrared monitoring of cerebral and myocardial oxygen sufficiency and circulatory parameters. Science 198, 1264-1267. doi: 10.1126/science.929199

Kishi, K., Kawaguchi, M., Yoshitani, K., Nagahata, T., and Furuya, H. (2003). Influence of patient variables and sensor location on regional cerebral oxygen saturation measured by INVOS 4100 near-infrared spectrophotometers. J. Neurosurg. Anesthesiol. 15, 302-306. doi: 10.1097/00008506200310000-00002

Madsen, P. L., Skak, C., Rasmussen, A., and Secher, N. H. (2000). Interference of cerebral near-infrared oximetry in patients with icterus. Anesth. Analg. 90, 489-493. doi: 10.1213/00000539-20000200000046

Murkin, J. M., Adams, S. J., Novick, R. J., Quantz, M., Bainbridge, D., Iglesias, I., et al. (2007). Monitoring brain oxygen saturation during coronary bypass surgery: a randomized, prospective study. Anesth. Analg. 104, 51-58. doi: 10.1213/01.ane.0000246814.29 $362 . \mathrm{f} 4$

Pollard, V., Prough, D. S., Demelo, A. E., Deyo, D. J., Uchida, T., and Stoddart, H. F. (1996). Validation in volunteers of a near-infrared spectroscope for monitoring brain oxygenation in vivo. Anesth. Analg. 82, 269-277. doi: 10.1213/00000539-19960200000010

Rasmussen, P., Dawson, E. A., Nybo, L., Van Lieshout, J. J., Secher, N. H., and Gjedde, A. (2007). Capillary-oxygenation-level-dependent near-infrared spectrometry in frontal lobe of humans. J Cereb. Blood Flow Metab. 27, 1082-1093. doi: $10.1038 /$ sj.jcbfm. 9600416

Sørensen, H., Rasmussen, P., Sato, K., Persson, S., Olesen, N. D., Nielsen, H. B., et al. (in press). External carotid artery flow maintains NIRSdetermined frontal lobe oxygenation during ephedrine administration. $\mathrm{Br} J$. Anaesth. doi: 10.1093/bja/aet481
Sørensen, H., Secher, N. H., Siebenmann, C., Nielsen, H. B., Kohl-Bareis, M., Lundby, C., et al. (2012). Cutaneous vasoconstriction affects nearinfrared spectroscopy determined cerebral oxygen saturation during administration of norepinephrine. Anesthesiology 117, 263-270. doi: 10.1097/ALN.0b013e3182605afe

Strangman, G. E., Zhang, Q., and Li, Z. (2014). Scalp and skull influence on near infrared photon propagation in the Colin 27 brain template. Neuroimage 85, 136-149. doi: 10.1016/ j.neuroimage.2013.04.090

Yoshitani, K., Kawaguchi, M., Miura, N., Okuno, T., Kanoda, T., Ohnishi, Y., et al. (2007). Effects of hemoglobin concentration, skull thickness, and the area of the cerebrospinal fluid layer on near-infrared spectroscopy measurements. Anesthesiology 106, 458-462. doi: 10.1097/00000 542-200703000-00009

Received: 01 December 2013; accepted: 22 December 2013; published online: 22 January 2014.

Citation: Sørensen H, Secher NH and Rasmussen P (2014) A note on arterial to venous oxygen saturation as reference for NIRS-determined frontal lobe oxygen saturation in healthy humans. Front. Physiol. 4:403. doi: 10.3389/fphys.2013.00403

This article was submitted to Integrative Physiology, a section of the journal Frontiers in Physiology.

Copyright (c) 2014 Sørensen, Secher and Rasmussen. This is an open-access article distributed under the terms of the Creative Commons Attribution License (CC BY). The use, distribution or reproduction in other forums is permitted, provided the original author(s) or licensor are credited and that the original publication in this journal is cited, in accordance with accepted academic practice. No use, distribution or reproduction is permitted which does not comply with these terms. 